\title{
Vapor Phase Digestion of Botanical Samples with Acids in Sealed Polytetrafluoroethylene Bomb
}

\author{
Isao KoJimA and Chuzo IIDA \\ Laboratory of Analytical Chemistry, Nagoya Institute of Technology, \\ Gokiso, Showa, Nagoya 466
}

\begin{abstract}
In a sealed PTFE bomb, the purification of acids used for decomposition and the decomposition of standard botanical samples (NIES-CRM No. 1 Pepperbush and No. 7 Tea Leaves) with these purified acid vapors were simultaneously carried out in the same vessel at an elevated temperature. A significant decrease in the sodium blank level even from the acids containing $800 \mu \mathrm{g} / \mathrm{g}$ sodium was observed. The very low blank level thus attained enabled sodium in Tea Leaves to be determined at as low a level as $0.30 \mu \mathrm{g} / \mathrm{g}$ in the sample solution, with a very good precision, by "one drop" flame emission spectrometry. With this decomposition method, iron, manganese and zinc in Pepperbush and manganese and zinc in Tea Leaves were satisfactorily determined.
\end{abstract}

Keywords Sodium determination, one drop flame emission spectrometry, vapor phase decomposition, standard botanical samples, PTFE bomb

In the determination of metals in the solid samples by atomic spectrometry, the most important step is generally the complete dissolution of the samples. For this purpose, either dry ashing or wet ashing method has been used, followed by the appropriate chemical treatments. In the field of trace analysis, contaminations from laboratory atmosphere, chemicals and containers will often make the determination of the elements of interest difficult. It is therefore essential to avoid such contamination, i.e., purified reagents and clean spaces should be required. To decrease the metal contamination from the acids used for decomposition of solid samples, acids specially purified by isopiestic distillation should be used for decomposition. On the other hand, the method by which the purification of the acids and the decomposition of samples with the vapor of this purified acid were simultaneously attained in a sealed or open vessel has also been described. ${ }^{1-6}$ This method was successfully applied to the determination of metals, e.g., $\mathrm{Fe}, \mathrm{Cr}, \mathrm{Ni}, \mathrm{Cu}, \mathrm{Zn}, \mathrm{Mn}, \mathrm{Cd}, \mathrm{Pb}$ and $\mathrm{As}$, in siliceous materials ${ }^{1-3}, \mathrm{Cu}$ and $\mathrm{Fe}$ in high purity inorganic materials ${ }^{4}, 10$ elements in aerosols ${ }^{5}$, and $\mathrm{Zn}, \mathrm{Cu}, \mathrm{Mn}$ and $\mathrm{Fe}$ in biological samples. ${ }^{6}$ But this method is not yet applied to the determination of trace metals like sodium, which can be easily contaminated from the atmosphere in the laboratory, or from containers, vessels, or reagents, or from manipulation.

In our laboratory, we achieved the reasonable and reproducible results for the determination of elements in solid samples weighing less than several hundred milligrams by decomposing the sample with an acid mixture in a sealed PTFE bomb. ${ }^{7-9}$ Even by this method, we were not able to avoid the contamination from the acids used for decomposition.

The present paper deals with the digestion of standard botanical samples with the acid vapor of nitric, hydrochloric and hydrofluoric acids in the sealed PTFE bomb and the complete decomposition by treating the digested solution with perchloric acid at elevated temperature. The sodium content in standard botanical samples, NIES-CRM No. 1 Pepperbush and No. 7 Tea Leaves, was satisfactorily and reproducibly determined with the low blank level by one drop flame emission spectrometry. To check on the complete decomposition of samples, manganese, iron and zinc were also determined by one drop flame atomic absorption spectrometry.

\section{Experimental}

\section{Apparatus}

The digestion was carried out by using a Tuf-Tainer Teflon PFA vial (inner vessel of $7 \mathrm{ml}$ capacity, TV-7 from Pierce Chemicals Co., through Gasukuro Kogyo Inc.) in a sealed PTFE vessel (outer vessel of $23 \mathrm{ml}$ capacity, N-25 from San-ai Kagaku) with a stainless steel jacket (Fig. 1). A Seiko Model 727 atomic absorption spectrophotometer was used with a $10 \mathrm{~cm}$ burner head or an air-acetylene flame and with a small PTFF funnel coupled directly to the nebulizer needle. The flame emission and atomic absorption signals were recorded on a fast-response strip-chart recorder. All 


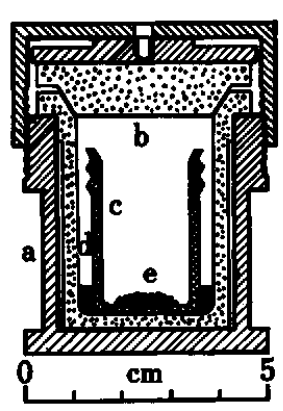

Fig. 1 Sealed PTFE decomposition vessel for vapor phase. a, stainless steel jacket; b, PTFE outer vessel; $c$, inner TufTainer vial; $d$, acid mixture for decomposition; e, sample.

measurements were carried out under the optimum operating conditions determined in our laboratory. The sample solution of $100 \mu \mathrm{l}$ was injected into the funnel with a micropipet (P-200) from Gilson.

\section{Reagents}

Metal stock solutions $\left(2 \mathrm{mg} / \mathrm{g}, 0.5 \mathrm{~mol} \mathrm{dm}^{-3}\right.$ hydrochloric or nitric acid) were prepared by dissolving metals (Fe and $\mathrm{Zn}, \mathbf{9 9 . 9 9 9 \%}$ from Mitsuwa Chemicals Co.) or metal compounds $\left(\mathrm{MnO}_{2}, \mathrm{CaCO}_{3}\right.$ and $\mathrm{MgO}$, "Specpure" from Johnson Matthey and recrystallized $\mathrm{KCl}$ and $\mathrm{NaCl}$ from Wako Pure Chemicals $\mathrm{Co}$.) in hydrochloric or nitric acid and diluting them with water by mass. Working mixed standard solutions were prepared by diluting the stock solutions with water and perchloric acid by mass to the appropriate concentrations. These solutions contain four metals of interest and $0.1 \mathrm{~mol} \mathrm{dm}^{-3}$ perchloric acid as in the sample solution. Matrices of $60 \mu \mathrm{g} / \mathrm{gCa}, 30 \mu \mathrm{g} / \mathrm{gMg}$ and $400 \mu \mathrm{g} / \mathrm{gK}$ for Tea Leaves and $300 \mu \mathrm{g} / \mathrm{gCa}, 100$ $\mu \mathrm{g} / \mathrm{gMg}$ and $300 \mu \mathrm{g} / \mathrm{gK}$ for Pepperbush are also added to these solutions, because the absence of matrices gave a lower sensitivity of sodium, i.e., $84 \%$ for former case. This phenomenon comes from the positive interference of matrices in sodium emission, in addition to the positive interference from perchloric acid itself. Acids of Super Special Grade from Wako Pure Chemicals Co. were used without further purification. Doubly distilled water from an all glass still was used throughout.

\section{Sample decomposition}

A sample of 30,100 or $300 \mathrm{mg}$ is introduced in an inner vessel of $7 \mathrm{ml}$ capacity without cap. Then the vessel is placed in a PTFE outer vessel with PTFE lid which contains $2 \mathrm{ml}$ of nitric, $0.2 \mathrm{ml}$ of hydrofluoric and $0.2 \mathrm{ml}$ of hydrochloric acids (see Fig. 1). After the outer vessel is inserted into the stainless steel jacket and the stainless steel cap is fastened tightly with a wrench, this decomposition vessel (PTFE bomb) is heated from the room temperature to $150^{\circ} \mathrm{C}$ in an air-oven, taking about $50 \mathrm{~min}$, and then kept at $150^{\circ} \mathrm{C}$ for $5 \mathrm{~h}$. After cooling the PTFE bomb to room temperature and taking out the inner vessel, $30 \mu \mathrm{l}, 100 \mu \mathrm{l}$ or $300 \mu \mathrm{l}$ of perchloric acid is added into the inner vessel according to the sample sizes used and the content in the inner vessel is evaporated to complete dryness in the specially designed glass evaporation chamber. The dry residue is dissolved in $1.5 \mathrm{ml}, 5.0 \mathrm{ml}$ or $15.0 \mathrm{ml}$ of $0.1 \mathrm{~mol} \mathrm{dm}^{-3}$ perchloric acid, respectively, and the final mass is weighed. These sample solutions are subjected to the determination of metals by one drop flame atomic absorption and emission spectrometry.

\section{Results and Discussion}

\section{Impurity in acids for decomposition}

Even with a PTFE decomposition bomb, metal contamination from the acids used for decomposition is still a very serious problem. In the determination of sodium in NIES-CRM No. 7 Tea Leaves, it was largely contaminated from the mixed acids used, i.e., nitric, hydrochloric, hydrofluoric and perchloric acids. A typical example is as follows: When $30 \mathrm{mg}$ of Tea Leaves was decomposed with $0.6 \mathrm{ml}$ of nitric, $0.1 \mathrm{ml}$ of hydrochloric, $0.1 \mathrm{ml}$ of perchloric, and $0.1 \mathrm{ml}$ of hydrofluoric acid by the conventional PTFE bomb method at the elevated temperature, and finally dissolved in $1.5 \mathrm{~g}$ of $0.1 \mathrm{~mol} \mathrm{dm}^{-3}$ perchloric acid after dryness of the decomposed content was achieved, the emission signal of sodium from the sample was only about one-third of the blank signal obtained from the acid mixtures. In this case, sodium content was not able to be correctly determined, because of this high sodium blank. Therefore, the sodium content in these acids should be determined first of all. The sodium content was flame-photometrically determined after the evaporation of $5 \mathrm{ml}$ of each acid and the dissolution of the residue in $1.5 \mathrm{~g}$ of $0.05 \mathrm{~mol} \mathrm{dm}^{-3}$ perchloric acid, respectively. The analytical results for sodium were $1.85,1.25,0.37$ and $0.03 \mu \mathrm{g} / \mathrm{g}$ in nitric, hydrochloric, perchloric and hydrofluoric acids, respectively. Therefore, perchloric acid was used in the final step for preparing standard and sample solutions, by reason of its low sodium content.

\section{Effect of time on decomposition}

With $30 \mathrm{mg}$ of standard botanical sample, NIESCRM No.1 Pepperbush, the time necessary to complete digestion with the acid mixture $\left(\mathrm{HNO}_{3}+\mathrm{HClO}_{4}+\mathrm{HF}+\right.$ $\mathrm{HCl})$ by the vapor phase method was examined at $150^{\circ} \mathrm{C}$ after elevation of temperature from 20 to $150^{\circ} \mathrm{C}$ over about $50 \mathrm{~min}$. Digestion was attained after $4 \mathrm{~h}$ but the final sample solution obtained by simply diluting the content with $0.1 \mathrm{~mol} \mathrm{dm}^{-3}$ perchloric acid was still a little viscous. The digestion of various amounts of the sample (30-300 mg) was also examined with a constant volume of the acid mixtures $(2.0 \mathrm{ml}$ $\mathrm{HNO}_{3}+1.0 \mathrm{ml} \mathrm{HClO}_{4}+0.2 \mathrm{ml} \mathrm{HCl}+0.2 \mathrm{ml} \mathrm{HF}$ and 2.0 $\mathrm{ml} \mathrm{HNO}+3+0.2 \mathrm{ml} \mathrm{HCl}+0.2 \mathrm{ml} \mathrm{HF}$ ). Irrespective of the presence of perchloric acid, $300 \mathrm{mg}$ of the sample was digested after $5 \mathrm{~h}$, but the final sample solution was still 
viscous, irrespective of the acid mixtures used. This shows clearly that perchloric acid is not effective for the decomposition of organic matter in the vapor phase. This is because the boiling point of perchloric acid is higher and the vapor pressure lower than those of the other acids. Therefore, as already described in our paper', the evaporation of the digested solution to complete dryness was necessary after the addition of perchloric acid, so that the viscosity of the final sample solution decreased. After this treatment, the dissolution of the residue in $0.1 \mathrm{~mol} \mathrm{dm}^{-3}$ perchloric acid gave the fluent final sample solution (non-viscous). Even with this step, contamination from perchloric acid and air was very little, because of the use of a small volume of perchloric acid and the evaporation of the solution in the special drying chamber. On the basis of these facts, the decomposition procedure for the determination of sodium was constructed, as written in the experimental section.

\section{Comparison of blank level}

Blank levels of sodium due to the acids, found by the conventional bomb method ${ }^{7-9}$ and by the present vapor phase decomposition method, are shown in Fig. 2,

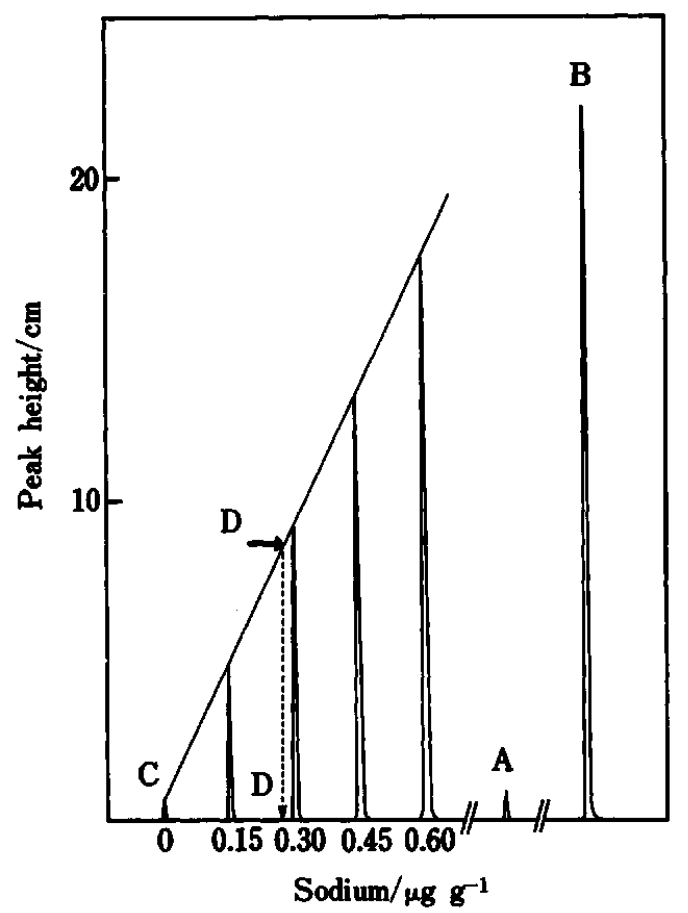

Fig. 2 Calibration graph for sodium and blank levels and sodium level from Tea Leaves. A: Blank level obtained by the present vapor method (see Table 1, A); acids used, $2.0 \mathrm{ml} \mathrm{HNO}_{3}+0.2 \mathrm{ml} \mathrm{HCl}+0.2 \mathrm{ml} \mathrm{HF}+0.03 \mathrm{ml} \mathrm{HClO}_{4}+$ $0.1 \mathrm{~mol} \mathrm{dm}^{-3} \mathrm{HClO}_{4} 1.5 \mathrm{ml}$. B: blank level obtained by the conventional bomb method ${ }^{7-9}$ (see Table 1, B); acids used, $0.6 \mathrm{ml} \mathrm{HNO}_{3}+0.1 \mathrm{ml} \mathrm{HCl}+0.1 \mathrm{ml} \mathrm{HF}+0.1$ $\mathrm{ml} \mathrm{HClO}_{4}+0.1 \mathrm{~mol} \mathrm{dm}^{-3} \mathrm{HClO}_{4} 1.5 \mathrm{ml}$. C: blank level of $0.1 \mathrm{~mol} \mathrm{dm}^{-3}$ perchloric acid (see Table 1, C). D: sodium level obtained from the $30 \mathrm{mg}$ of Tea Leaves dissolved in the final solution $(1.5 \mathrm{~g}$ ) (see Table $1, \mathrm{D}$ ). along with the calibration graph of sodium. The comparison of the sodium blanks found by these two methods is given in Table 1, with the sodium data obtained with $30 \mathrm{mg}$ of Tea Leaves. The blank level obtained by the present method (A in Fig. 2 and 0.054 $\mu \mathrm{g}$ in Table 1) is much lower than that obtained by the conventional bomb method (B in Fig. 2 and $1.26 \mu \mathrm{g}$ in Table 1). Blank level A in Fig. $2(0.054 \mu \mathrm{g}$ in Table 1) is a bit higher than sodium level in $0.1 \mathrm{~mol} \mathrm{dm}^{-3}$ perchloric acid, i.e., $\mathrm{C}$ in Fig. $2(0.03 \mu \mathrm{g}$ in Table 1), which corresponds to the theoretical value calculated from the sodium content in concentrated perchloric acid. This difference in the sodium content $(0.024 \mu \mathrm{g})$ seems to be caused by the container itself. The blank level obtained by the present method did not change even with the addition of $2 \mathrm{mg}$ of sodium in the acids. This fact shows that no contamination of the sample from the acids occurs even when rather impure acid mixtures are used for decomposition. The blank value $(1.26 \mu \mathrm{g})$ found by the conventional bomb method agreed well with the theoretical value $(1.24+0.03 \mu \mathrm{g})$ calculated from the sodium contents in each acid volume used. Also, the sodium content in $30 \mathrm{mg}$ of Tea Leaves calculated from the value found $(0.47 \mu \mathrm{g}$ in Table 1) and the blank value $(0.054 \mu \mathrm{g}, A$ in Table 1) was $0.42 \mu \mathrm{g}$ (D in Table 1 and Fig. 2). This value agreed well with the value obtained by Okamoto. ${ }^{10} \mathrm{On}$ the basis of these facts, the present method was applied to the determination of sodium in two standard botanical samples: NIES-CRM No. 1 Pepperbush and No. 7 Tea Leaves.

\section{Application to standard botanical materials}

The analytical results for sodium obtained with 30 $300 \mathrm{mg}$ of standard materials are shown in Tables 2 and 3 along with the analytical results for iron,

Table 1 Comparison of sodium blank found by the two methods ${ }^{a}$

\begin{tabular}{|c|c|c|c|}
\hline & \multicolumn{2}{|c|}{ Procedure blank $/ \mu \mathrm{g}$} & \multirow{2}{*}{ 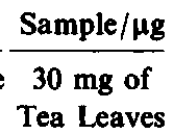 } \\
\hline & $\begin{array}{l}\text { Conventional } \\
\text { bomb method }\end{array}$ & $\begin{array}{l}\text { Vapor phase } \\
\text { method }\end{array}$ & \\
\hline Theoretical & $1.24^{\mathrm{b}}$ & $3.96^{\mathrm{b}}$ & $0.42^{\mathrm{c}}$ \\
\hline Total found & 1.26 (B) & $0.054(A)^{d}$ & 0.47 \\
\hline $0.1 \mathrm{~mol} \mathrm{dm}^{-3} \mathrm{HClO}_{4}$ & $0.03(\mathrm{C})$ & 0.03 & 0.03 \\
\hline Sample & 0 & 0 & 0.42 (D) \\
\hline
\end{tabular}

A, B, C and D are given in Fig. 1.

a. In all cases the final mass of solutions is $1.5 \mathrm{~g}$. All figures but the theoretical one are the absolute mass of sodium in the final mass of solution $(1.5 \mathrm{~g})$.

b. Absolute mass of sodium calculated from the sodium content in the acids and the acid volume used.

c. Absolute mass of sodium calculated from the reported values. ${ }^{10}$

d. Even for the addition of $\mathbf{2} \mathbf{m g}$ of sodium in the acid used for decomposition, the same blank value is obtained. 
Table 2 Analytical results for elements in NIES-CRM No. 1 Pepperbush

\begin{tabular}{|c|c|c|c|c|c|}
\hline \multirow{2}{*}{$\begin{array}{c}\text { Sample } \\
\text { taken }\end{array}$} & \multicolumn{4}{|c|}{ Element found $/ \mu \mathrm{g} \mathrm{g}^{-1}$} & \multirow{2}{*}{$n$} \\
\hline & $\mathrm{Na}$ & $\mathbf{F e}$ & $\mathbf{M n}$ & $\mathbf{Z n}$ & \\
\hline $300 \mathrm{mg}$ & 104 & 209 & 2060 & 356 & 2 \\
\hline $100 \mathrm{mg}$ & $102 \pm 1$ & $211 \pm 3$ & $2100 \pm 15$ & $351 \pm 5$ & 4 \\
\hline $30 \mathrm{mg}$ & $105 \pm 2$ & $214 \pm 5$ & $2170 \pm 30$ & $361 \pm 8$ & 8 \\
\hline \multicolumn{6}{|c|}{ Blank assuming (100 $\mathrm{mg}$ of sample) } \\
\hline & 1.8 & ND & ND & ND & 8 \\
\hline \multicolumn{6}{|c|}{ Conventional bomb method } \\
\hline & $107 \pm 3$ & $217 \pm 3$ & $2100 \pm 20$ & $349 \pm 4$ & 5 \\
\hline \multicolumn{6}{|c|}{ Blank assuming ( $100 \mathrm{mg}$ of sample) } \\
\hline & 41 & ND & ND & ND & \\
\hline \multicolumn{6}{|c|}{ Certified value } \\
\hline & $106 \pm 13$ & $205 \pm 17$ & $2030 \pm 170$ & $340 \pm 20$ & \\
\hline
\end{tabular}

ND, not detected; $n$, number of experiments.

manganese and zinc in Pepperbush and for iron and zinc in Tea Leaves. Irrespective of the sample sizes used, the analytical results agreed well with each other and with the certified ${ }^{11}$ values and our previous ones. ${ }^{9}$ The sodium blank value obtained by assuming $100 \mathrm{mg}$ of sample was $1.8 \mu \mathrm{g} / \mathrm{g}$ for each case, no blank value for the other elements was detected. This low blank level enabled elements at very low level in final sample solution to be determined with a very good precision.

In conclusion, the main advantage of the present method is its simplicity and freedom from the contamination due to any reagents used for digestion, i.e., a significant decrease in the blank level compared with the conventional bomb method. However, this advantage may be partly destroyed by the application being limited to a comparatively small amount of sample, by the long decomposition time or by the contamination coming through the container being in the air in the weighing step. If these disadvantages are overcome, the present method can be widely applied to the decomposition of samples for the determination of trace elements in various kinds of materials by the combined use of sensitive analytical methods.
Table 3 Analytical results for elements in NIES-CRM No. 7 Tea Leaves

\begin{tabular}{|c|c|c|c|c|}
\hline \multirow{2}{*}{$\begin{array}{c}\text { Sample } \\
\text { taken }\end{array}$} & \multicolumn{3}{|c|}{ Element found $/ \mu \mathrm{g} \mathrm{g}^{-1}$} & \multirow{2}{*}{$n$} \\
\hline & $\mathbf{N a}$ & Mn & $\mathbf{Z n}$ & \\
\hline $300 \mathrm{mg}$ & $14.1 \pm 1.0$ & $706 \pm 13$ & $33.8 \pm 0.7$ & 7 \\
\hline $100 \mathrm{mg}$ & $13.6 \pm 0.6$ & $709 \pm 9$ & $33.8 \pm 0.4$ & 7 \\
\hline $30 \mathrm{mg}$ & $13.5 \pm 0.6$ & $713 \pm 4$ & $33.3 \pm 0.6$ & 7 \\
\hline \multicolumn{5}{|c|}{ Blank assuming (100 $\mathrm{mg}$ of sample) } \\
\hline & 1.8 & ND & ND & 14 \\
\hline \multicolumn{5}{|c|}{ Conventional bomb method } \\
\hline & $15-20$ & $711 \pm 9$ & $33.0 \pm 0.3$ & 6 \\
\hline \multicolumn{5}{|c|}{ Blank assuming ( $100 \mathrm{mg}$ of sample) } \\
\hline & 41 & ND & ND & \\
\hline Reported $^{a}$ & 14.9 & 701 & 34.1 & \\
\hline
\end{tabular}

a. K. Okamoto, private communication. ${ }^{10}$

$n$, number of experiments.

The authors wish to thank Mrs. K. Hirose for her experimental assistance. One of us (I.K.) would like to thank the Ishida Foundation for financial support.

\section{References}

1. J. W. Mitchell and D. L. Nash, Anal. Chem., 46, 326 (1974).

2. C. Feldman, Anal. Chem., 49, 825 (1977).

3. V. J. Phelan and R. J. W. Powell, Analyst [London], 109; 1269 (1984).

4. J. F. Woolley, Analyst [London], 100, 896 (1975).

5. T. R. Stolzenburg and A. W. Andren, Anal. Chim. Acta, 118, 377 (1980).

6. A. D. Thomas and L. E. Smythe, Talanta, 20, 469 (1973).

7. C. Iida, T. Uchida and I. Kojima, Anal. Chim. Acta, 113, 365 (1980).

8. T. Uchida, I. Kojima and C. Iida, Anal. Chim. Acta, 116, 205 (1980)

9. I. Kojima, T. Uchida and C. Iida, Anal. Sci., 2, 225(1986).

10. K. Okamoto, private communication.

11. K. Okamoto and K. Fuwa, Anal. Chem., 50, 1950 (1985).

(Received August 22, 1986)

(Accepted September 22, 1986) 